Pesq. Vet. Bras. 30(8):670-675, agosto 2010

\title{
Parâmetros hematológicos do roedor fossorial Ctenomys lami (Rodentia, Ctenomidae) no estado do Rio Grande do Sul ${ }^{1}$
}

\author{
Gisele G. Stein ${ }^{*}$, Luciana A. Lacerda ${ }^{3}$, Nicole Hlavac ${ }^{3}$, José F.B. Stolz ${ }^{4}$, \\ Ingrid V. Stein ${ }^{3}$, Thales R.O. Freitas ${ }^{4}$ e André S. Carissimi ${ }^{2}$
}

\begin{abstract}
Stein G.G., Lacerda L.A., Hlavac N., Stolz J.F.B., Stein I.V., Freitas T.R.O. \& Carissimi A.S. 2010. [Hematological parameters of fossorial rodent Ctenomys lami (Rodentia, Ctenomidae) in Rio Grande do Sul, Brazil.] Parâmetros hematológicos do roedor fossorial Ctenomys lami (Rodentia, Ctenomidea) no Rio Grande do Sul. Pesquisa Veterinária Brasileira 30(8):670-675. Departamento de Medicina Animal, Faculdade de Medicina Veterinária, Universidade Federal do Rio Grande do Sul, Av. Bento Gonçalves 9090, Porto Alegre, RS 91540-000, Brazil. E-mail: gisele.stein@ufrgs.br

The hematological profile was determined in three populations of Ctenomys lamithat inhabits three different areas nominated as $\mathrm{A}$ and $\mathrm{B}$, affected by cattle production, and $\mathrm{C}$, without human impact, all of them in southern Brazil, under the same geologic formation. Sixty two individuals were collected. The packed cell volume (PCV) values, hemoglobin ( $\mathrm{Hb})$ and red blood cell (RBC) count presents statistic significant differences between males and females. $\mathrm{PCV}$ and $\mathrm{Hb}$ values were lower in comparison with other subterranean rodents, which could be related to the food searching behavior or soil characteristic of the species. Significant statistic differences were found to for $\mathrm{Hb}$, mean corpuscular hemoglobin concentration $(\mathrm{MCHC})$ and lymphocytes between animals belonging to $A$ and $C$ areas. The $P C V$ values were higher for animals from areas $A$ and $B$, with significance only between $A$ and $C$. Some of these alterations may suggest a modification on stress levels of the animals inhabiting areas $A$ and $B$ with anthropic alterations, or maybe just an inherited characteristic. Significant statistic differences were found either in mean corpuscular volume (MCV) between $A$ and $C$ areas, and platelets between $A$ and $B$ areas. No Kurloff cells were observed in the blood smear from analyzed individuals. The hematological values founded for Ctenomys lamiare an important information for this species, which can be used for future research and management.
\end{abstract}

INDEX TERMS: Hematology, blood, fossorial rodent, tuco-tuco, Ctenomys lami.

RESUMO.- O perfil hematológico sanguíneo foi determinado em três populações de Ctenomys lami, em áreas denominadas $\mathrm{A}$ e $\mathrm{B}$, impactadas pela bovinocultura, e $\mathrm{C}$, sem impacto antrópico, ambas no sul do Brasil. Sessenta e dois animais foram coletados ao total. Os valores de

\footnotetext{
${ }^{1}$ Recebido em 2 de maio de 2009.

Aceito para publicação em 28 de julho de 2010.

2 Departamento de Medicina Animal, Faculdade de Medicina Veterinária, Universidade Federal do Rio Grande do Sul (UFRGS), Av. Bento Gonçalves 9090, Bairro Agronomia, Porto Alegre, RS 91540-000, Brasil. "Autor para correspondência: gisele.stein@ufrgs.br

${ }^{3}$ Laboratório de Análises Clínicas Veterinárias (UFRGS), Porto Alegre, RS.

${ }^{4}$ Departamento de Genética, Faculdade Ciências Biológicas, UFRGS, Av. Bento Gonçalves 9500, Prédio 43323, Porto Alegre, RS 91501970.
}

hematócrito $(\mathrm{Ht})$, hemoglobina $(\mathrm{Hb})$ e eritrócitos apresentaram diferenças significativas entre machos e fêmeas. Os valores médios de $\mathrm{Ht}$ e a $\mathrm{Hb}$ encontrados na espécie foram mais baixos em comparação com os de outras espécies de roedores subterrâneos, podendo estes valores estarem relacionados ao habitat de forrageio ou às características do solo. Também foram encontradas diferenças significativas nas médias de hemoglobina, $\mathrm{CHCM}$ e linfócitos em animais das áreas $\mathrm{A}$ e $\mathrm{B}$ em relação à área $\mathrm{C}$. $\mathrm{O}$ valor da média dos hematócritos dos animais entre as áreas foi mais elevado nas áreas $A$ e $B$, porém significativamente diferentes entre $\mathrm{A}$ e $\mathrm{C}$. Algumas dessas alterações sugerem a relação dos valores encontrados com o estresse dos animais em relação a áreas impactadas. Variações significativas no VCM foram encontradas entre os animais das áreas $\mathrm{A}$ e $\mathrm{C}$, e também nas plaquetas destes entre as 
áreas A e B. Não foram observados Corpúsculo de Kurloff no sangue dos animais analisados. Os valores hematológicos encontrados nesses espécimes de Ctenomys lami fornecem informações importantes sobre a espécie e podem ser úteis em outras pesquisas.

TERMOS DE INDEXAÇÃO: Hematologia, roedor fossorial, tucotuco, Ctenomys lami.

\section{INTRODUÇÃO}

O gênero Ctenomys, pertencente à subordem Hystricomorpha (Woods 2005) constitui um amplo grupo de aproximadamente 56 espécies de roedores fossoriais (Reig et al 1990, Lacey et al. 2000). A espécie Ctenomys lami está presente em uma região arenosa chamada de Coxilha das Lombas, que se estende do norte do Rio Guaíba em direção ao noroeste dos bancos de areia da lagoa dos Barros, cercada por lagoas e banhados no sul do Brasil (Freitas 2001). Devido à topografia da região e à distribuição geográfica dos diferentes cariótipos encontrados nas populações de C. lami, foi proposta a separação destas em quatro blocos populacionais ao longo dos $78 \mathrm{~km}$ das Coxilhas das Lombas: Blocos A, B, C e D (Fig.1) (Freitas 1990). Estes animais apresentam algumas adaptações fisiológicas que são impostas em decorrência das características encontradas na vida subterrânea. A prevalência de hipóxia e hipercapnia atmosférica acaba gerando modificações fisiológicas não encontradas em outros animais (Maclean 1981), apresentando altas concentrações de hematócrito e hemoglobina quando comparados a espécies de roedores não subterrâneos (Lacey 2000). Algumas adaptações morfológicas também são encontradas, incluindo o aumento na densidade capilar do esqueleto, músculo cardíaco e tecido pulmonar, juntamente com um considerado aumento na quantidade de mitocôndrias encontradas nos músculos esqueléticos (Widmer et al. 1997).

Em alguns roedores da subordem Hystricomorpha ob- servam-se células que eventualmente exibem inclusões citoplasmáticas, conhecidas como Corpúsculo de Kurloff (Jain 1986, Hawkey \& Dennet 1989). Estas células são conhecidas como Células de Kurloff (KC), sendo mononucleares com propriedades de linfócitos e monócitos (Eremin et al. 1980). A função destas células não está bem esclarecida, embora, em Cavia porcellus, possuam envolvimento na atividade imune (Dobout et al. 1984) e propriedades anticancerígenas (Debout et al. 1999). Em capivaras (Hydrochoerus hydrochaeris), existe a presença destas Células de Kurloff no sangue periférico e em alguns órgãos, como por exemplo, o baço. Em fases gestacionais e lactacionais, as capivaras apresentam um aumento significativo na contagem de KC nos tecidos, podendo também ser vistas no sangue periférico em fêmeas prenhes (Jara et al. 2005). Em Cavia porcellus, um aumento destas células é observada em fêmeas durante a prenhes e em ambos os sexos após a administração de estrógenos (Dean \& Muir 1970). Em espécies do gênero Ctenomys, não existe conhecimento sobre a presença dessas células o sangue.

São escassos os dados que se encontram na literatura sobre parâmetros hematológicos para o gênero Ctenomys. Devido a essa falta de informação sobre os roedores deste gênero no Brasil, este trabalho tem por objetivo contribuir para a definição do perfil hematológico do roedor fossorial Ctenomys lami em três populações no sul do Brasil, comparando as diferenças entre as áreas de vida, sexo dos animais e verificar a possível existência de Células de Kurloff nesses animais.

\section{MATERIAL E MÉTODOS}

Os animais foram capturados em vida livre, em três regiões distintas: Área A (Distrito de Itapuã, 30¹7'31,2"S 5058'31,6"O), Área B (Município de Viamão, 308'0,8"S 5054'38,2"O), ambas com impacto antrópico; e Área C (Município de Viamão, Unidade de Conservação Refúgio de Vida Silvestre Banhado dos Pachecos, distrito de Águas Claras, $30^{\circ} 05^{\prime 3} 31.2^{\prime \prime} \mathrm{S} 050^{\circ}$

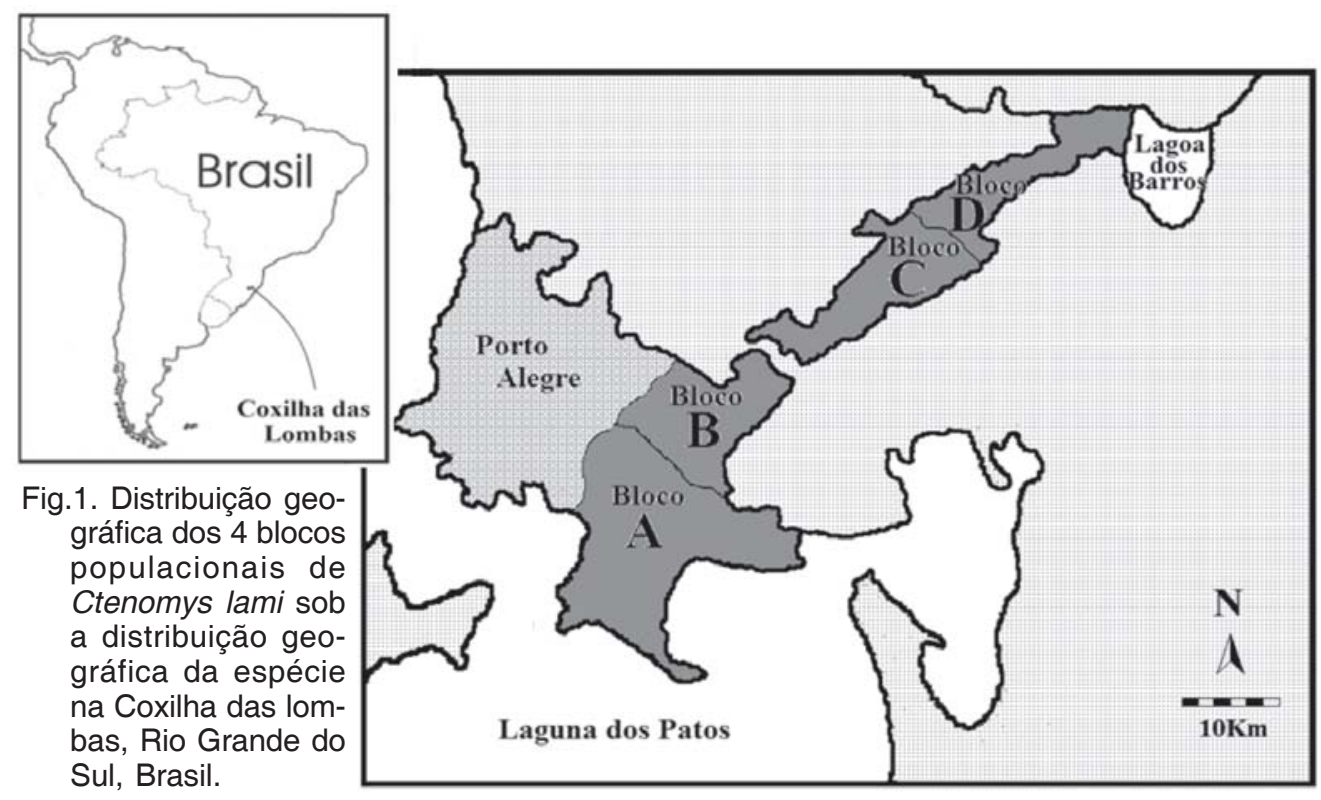

Pesq. Vet. Bras. 30(8):670-675, agosto 2010 
50'35.00”). Os procedimentos utilizados com os animais seguem as diretrizes aprovadas pela American Society of Mammalogists (Animal Care and Use Committee 1998). A captura foi realizada durante os meses de junho a setembro do ano de 2008 , com ajuda de armadilhas tipo trampa no "0"5 colocadas na entrada do túnel e fixadas externamente através de estacas de madeira. Os animais capturados foram pesados e anestesiados com $20 \mathrm{mg} / \mathrm{kg}$ de Cetamina ${ }^{6}$, por via intramuscular. Exames clínicos foram realizados para avaliação da saúde geral, presença de ectoparasitas, registro do sexo e seleção dos animais que apresentaram boas condições corporais. Os parasitas encontrados foram coletados, conservados em álcool $70^{\circ}$ e encaminhados para a identificação. Não foram feitos exames para averiguação de endoparasitas. Capturou-se 23 animais na área $A$ (11 machos e 12 fêmeas), 19 animais na área $B$ (7 machos e 12 fêmeas), e 20 animais na área $C$ (7 machos e 13 fêmeas), totalizando 62 espécimes de Ctenomys lami, todos indivíduos adultos. As amostras de sangue foram coletadas através de punção da veia cava cranial, respeitando-se o total de $10 \%$ do volume sanguíneo de cada animal. Imediatamente após a coleta, o sangue foi transferido para micro tubos ${ }^{7}$ com anticoagulante EDTA (Ácido Etilenodiamino Tetra-Acético) para a realização do hemograma. As amostras foram identificadas e mantidas sob refrigeração durante o transporte até o laboratório. Observado o completo retorno anestésico, todos os animais foram liberados em seus devidos túneis.

No momento em que as amostras eram recebidas no laboratório, o esfregaço sanguíneo era realizado e as lâminas eram armazenadas em recipientes adequados, protegidas da luz e de contaminação. Para a coloração do material, foi utilizado o corante de Wright $\left(\right.$ Merck $\left.^{\circledR}\right)$. Os esfregaços foram avaliados após a realização das outras etapas. As contagens de eritrócitos e

${ }^{5}$ Oneida Victor $\mathrm{n}$ 0. Oneida Victor Inc, Cleveland, $\mathrm{OH}$.

${ }^{6}$ Cetamin. Rhobifarma, São Paulo, SP.

${ }^{7}$ MiniCollect. Greiner Bio-One, São Paulo, SP. leucócitos foram realizadas manualmente em câmara hematimétrica (Neubauer improved, Labor Optik) utilizando-se respectivamente as soluções diluentes Hayen e Türk (Newprov). O hematócrito $(\mathrm{Ht})$ foi determinado pelo método do microhematócrito (10.000 rpm ou $9.520 \mathrm{~g}$ por 5 minutos) em microcentrífuga (Sigma 1-15). A concentração de hemoglobina corpuscular média (CHCM) e o volume corpuscular médio (VCM) foram calculados de acordo com Jain (1986). A dosagem de hemoglobina foi realizada através do método do cianeto de hemiglobina (Labtest Diagnóstica SA) e determinada por espectrofotometria (Labquest). As proteínas plasmáticas totais (PPT) foram determinadas através da refratometria (Instrutherm). A partir do esfregaço sanguíneo corado foi realizada a contagem diferencial de leucócitos, a análise da morfologia celular e a avaliação da quantidade estimada de plaquetas.

As análises estatísticas foram realizadas com auxílio do pacote estatístico $\mathrm{R}$ e do programa BioStat. As variáveis foram comparadas entre os sexos com o teste $\mathrm{T}$ e KolmogorovSmirnov, conforme a normalidade ou ausência desta na distribuição dos dados, respectivamente. As variáveis contínuas foram comparadas entre as áreas com os testes de Anova de duas vias (sexo e área) ou Kruskall-Wallis. Calcularam-se os intervalos de confiança de $95 \%$ para as estimativas dos parâmetros hematológicos. Foram considerados significativos valores de $\mathrm{P}<0,05$.

\section{RESULTADOS E DISCUSSÃO}

O perfil da amostragem do estudo se encontra no Quadro 1. O exame físico dos 62 espécimes de Ctenomys lami indicou uma boa condição corporal sem evidências de desidratação nos animais. Todos os animais capturados na área $A$ estavam extremamente parasitados por pulgas do gênero Polygenis. Valores de referência para um perfil hematológico da espécie foram calculados e estão apresentados no Quadro 2.

Quadro 1. Perfil da amostragem do estudo realizado com a espécie Ctenomys lami, em três áreas na região da Coxilha das Lombas, Rio Grande do Sul, Brasil

\begin{tabular}{|c|c|c|c|}
\hline Variáveis & Área $\mathrm{A}$ & Área B & Área C \\
\hline $\begin{array}{l}\text { Machos (n) } \\
\text { Fêmeas (n) }\end{array}$ & $\begin{array}{l}11 \\
12\end{array}$ & $\begin{array}{c}7 \\
12\end{array}$ & $\begin{array}{c}7 \\
13\end{array}$ \\
\hline $\begin{array}{l}\text { Massa corporal machos }(\mathrm{g}) \\
\text { Massa corporal fêmeas }(\mathrm{g})\end{array}$ & $\begin{array}{l}219,7 \pm 50,7 \\
206,7 \pm 27,7\end{array}$ & $\begin{array}{c}285 \pm 61,6 \\
193,6 \pm 25,7\end{array}$ & $\begin{array}{l}231,4 \pm 51,5 \\
191,4 \pm 33,1\end{array}$ \\
\hline $\begin{array}{l}\text { Comprimento total a machos }(\mathrm{cm}) \\
\text { Comprimento total a fêmeas }(\mathrm{cm})\end{array}$ & $\begin{array}{l}274 \pm 18,8 \\
257,5 \pm 18\end{array}$ & $\begin{array}{c}290,8 \pm 14,9 \\
262,4 \quad 11,2\end{array}$ & $\begin{array}{c}228,4 \pm 101,2 \\
258,8 \pm 13,9\end{array}$ \\
\hline $\begin{array}{l}\text { Estação de coleta } \\
\text { Faixa etária }\end{array}$ & $\begin{array}{l}\text { Inverno } \\
\text { Adultos }\end{array}$ & $\begin{array}{l}\text { Inverno } \\
\text { Adultos }\end{array}$ & $\begin{array}{l}\text { Inverno } \\
\text { Adultos }\end{array}$ \\
\hline $\begin{array}{l}\text { Avaliação de saúde geral }{ }^{b} \\
\text { Atividade reprodutiva }\end{array}$ & $\begin{array}{l}\text { Saudáveis } \\
\text { Sem }\end{array}$ & $\begin{array}{l}\text { Saudáveis } \\
\text { Sem }\end{array}$ & $\begin{array}{l}\text { Saudáveis } \\
\text { Sem }\end{array}$ \\
\hline $\begin{array}{l}\text { Grau de ectoparasitismo }{ }^{c} \\
\text { Impacto antrópico }\end{array}$ & $\begin{array}{l}+++ \\
\text { Presente }\end{array}$ & $\stackrel{+}{+}+$ & $\stackrel{+}{+}$ \\
\hline
\end{tabular}

a O comprimento total do corpo compreende as medidas da ponta do focinho até ponta da cauda.

b A saúde geral foi avaliada de acordo com o estado corporal (magro, normal, obeso), mucosas (pálidas, rosadas, hiperêmicas), lesão externa (ausente ou presente).

c Grau de ectoparasitismo: +++ (mais de 15 pulgas/animal), ++ (entre 5 a 10 pulgas/animal), + (menos de 5 pulgas/animal). As massas corporais e comprimentos totais estão expressos em média \pm desvio padrão. 
Quadro 2. Média e intervalos de confiança de $95 \%$, do perfil hematológico do roedor fossorial Ctenomys lami, separado por sexo, no Rio Grande do Sul, Brasil

\begin{tabular}{lcc}
\hline Parâmetros hematológicos & Machos $\mathrm{n}=23$ & Fêmeas $\mathrm{n}=39$ \\
\hline Hematócrito $(\%)$ & $36,7(35,4-38,0)$ & $33,9^{*}(32,8-35,0)$ \\
Hemoglobina $(\mathrm{g} / \mathrm{dL})$ & $11,8(10,9-12,7)$ & $10,4^{*}(9,9-10,8)$ \\
Eritrócitos $\left(\mathrm{x} 10^{6} / \mathrm{mL}\right)$ & $5,7(5,4-6,1)$ & $5,1^{*}(5,0-5,3)$ \\
Plaquetas $\left(\times 10^{3} / \mathrm{mL}\right)$ & $477,7(440,1-515,2)$ & $456,3(434,6-478,0)$ \\
VCM (fL) & $64,4(62,0-66,9)$ & $66,2(64,4-68,0)$ \\
CHCM $(\%)$ & $32,0(30,4-33,7)$ & $30,7(29,6-31,7)$ \\
Leucócitos $(/ \mathrm{mL})$ & $8104,4(6927-9281)$ & $8261,5(7124-9398)$ \\
Neutrófilos bastonetes $(/ \mathrm{mL})$ & 0 & $2,1(0-6,2)$ \\
Neutrófilos segmentados $(/ \mathrm{mL})$ & $4168,1(3318,8-5017,4)$ & $3471,6(2856,7-4086,6)$ \\
Linfócitos $(/ \mathrm{mL})$ & $3138,9(2379,5-3898,3)$ & $3892,9(3050,9-4735,0)$ \\
Monócitos $(/ \mathrm{mL})$ & $156,5(97,7-215,2)$ & $211,7(156,1-267,4)$ \\
Basófilos $(/ \mathrm{mL})$ & $12,6(0-25,5)$ & $22,7(8,5-36,8)$ \\
Eosinófilos $(/ \mathrm{mL})$ & $329,8(106,4-553,1)$ & $342,1(182,1-501,3)$ \\
\end{tabular}

Diferenças significativas entre os sexos $(\mathrm{P}<0,05)$.

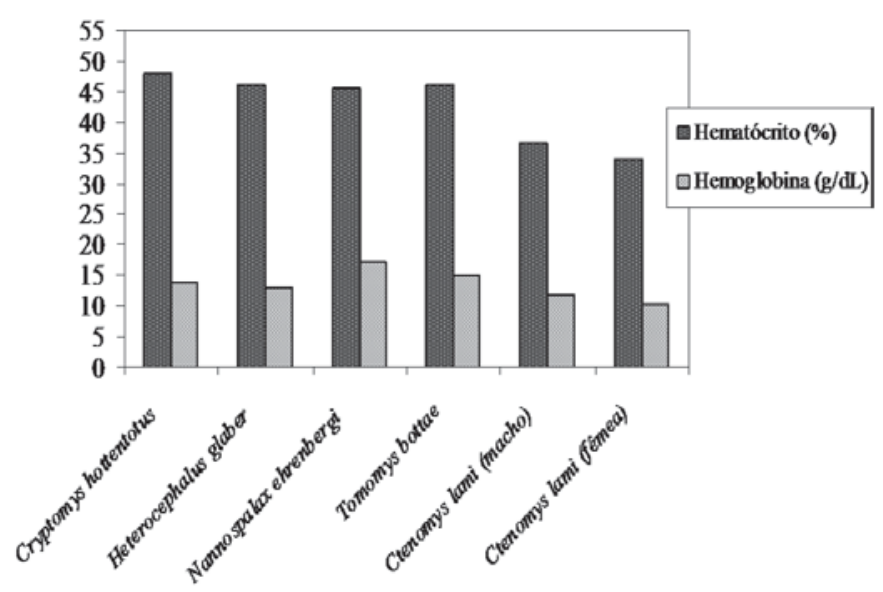

Fig.2. Comparação entre os valores médios de Hematócrito (\%) e Hemoglobina $(\mathrm{g} / \mathrm{dL})$ de diferentes espécies de roedores subterrâneos com a espécie de roedor subterrâneo Ctenomys lami. Fontes: Buffenstein (2000), Johansen et al. (1976), Lechner (1976), Arieli \& Shkolnik (1977).
Os valores encontrados para hematócrito, hemoglobina e eritrócitos nas fêmeas apresentam valores significativamente inferiores quando comparados aos valores encontrados para os machos da mesma espécie.

O transporte de oxigênio em roedores subterrâneos é distinto, pois a baixa concentração de oxigênio encontrada em seus túneis acaba levando a uma adaptação fisiológica do organismo destes animais, apresentando altas concentrações no hematócrito e hemoglobina quando comparados a espécies de roedores não subterrâneos (Lacey 2000).

Ao contrário do esperado, apesar de possuir um modo de vida subterrâneo, $C$. lami apresenta valores de $\mathrm{HT}$ e $\mathrm{Hb}$ bastante abaixo dos valores encontrados para outras espécies com este mesmo modo de vida (Fig.2).

A alimentação de espécies do gênero Ctenomys é composta em $97 \%$ de partes aéreas das plantas (Comparatore et al. 1995). O tempo de alimentação está positivamente correlacionado com a quantidade de tempo em que estes

Quadro 3. Média \pm desvio padrão dos valores de hemograma em três áreas com a presença de Ctenomys lami (Áreas A e B - com impacto antrópico, área C sem impacto antrópico), no Rio Grande do Sul, Brasil

\begin{tabular}{|c|c|c|c|}
\hline & $\begin{array}{l}\text { Área A } \\
n=23\end{array}$ & $\begin{array}{c}\text { Área B } \\
n=19\end{array}$ & $\begin{array}{c}\text { Área C } \\
n=20\end{array}$ \\
\hline Eritrócitos $\left(\times 10^{6} / \mathrm{mL}\right)$ & $5,36 \pm 0,5$ & $5,41 \pm 0,8$ & $5,31 \pm 0,6$ \\
\hline Hematócrito (\%) & $36,35^{a} \pm 2,4$ & $35,05^{\mathbf{a}, \mathbf{b}} \pm 4,3$ & $33,2^{b} \pm 2,8$ \\
\hline Hemoglobina ( $g / d L)$ & $11,6^{a} \pm 1,7$ & $11,4^{a} \pm 2,03$ & $9,7^{b} \pm 1,1$ \\
\hline $\operatorname{VCM}(\mathrm{fL})$ & $68,1^{a} \pm 4,6$ & $65,3^{a, b} \pm 6,4$ & $62,9^{\mathbf{b}} \pm 4,8$ \\
\hline $\mathrm{CHCM}(\%)$ & $31,87^{a} \pm 3,6$ & $32,40^{a} \pm 4,1$ & $29,2^{b} \pm 1,6$ \\
\hline Plaquetas & $490,9^{a} \pm 80,3$ & $427,1^{b} \pm 68,7$ & $459,4^{\mathbf{a}, \mathbf{b}} \pm 49,9$ \\
\hline 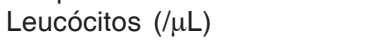 & $8834,8 \pm 3079,2$ & $8531,6 \pm 3756,2$ & $7165 \pm 2670,9$ \\
\hline Neutrófilo Segmentado $(/ \mu \mathrm{L})$ & $4063,6 \pm 1725,6$ & $2796,6 \pm 1891,1$ & $4233,05 \pm 1981,1$ \\
\hline 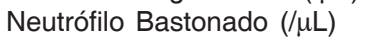 & $0 \pm 0$ & $0 \pm 0$ & $0 \pm 0$ \\
\hline Linfócito(/uL) & $4181^{a} \pm 2202,2$ & $4154^{a} \pm 2760,1$ & $2446,5^{b} \pm 1597,01$ \\
\hline 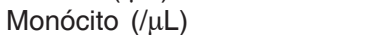 & $222,4 \pm 151,6$ & $204,9 \pm 192,2$ & $142,4 \pm 131,03$ \\
\hline Basófilos (/uL) & $0 \pm 52$ & $0 \pm 0$ & $0 \pm 34,6$ \\
\hline Eosinófilos $(/ \mu \mathrm{L})$ & $192 \pm 496,6$ & $216 \pm 518,6$ & $219 \pm 50$ \\
\hline
\end{tabular}

Os dados estão expressos em média \pm desvio padrão, considerando significância estatística com valores de $\mathrm{P}<0,05{ }^{\mathrm{a}, \mathrm{b}}$ Indicam diferenças significativas em cada área. A diferença estatística está indicada por letras diferentes. 
animais despendem fora de seus túneis (Willian \& Cameron 1986). Em vista disso, sugere-se que os baixos valores encontrados de hematócrito e hemoglobina podem estar relacionados a um menor tempo de exposição a baixas concentrações de oxigênio por estes animais em comparação a outros gêneros de roedores subterrâneos em que a alimentação é em maior parte constituída por raízes e dentro de seus túneis.

De acordo com Arieli (1979), as trocas gasosas entre os habitats subterrâneos e o meio externo dependerão das propriedades de difusão do solo, variando de acordo com o tipo de solo e umidade presente neste. De acordo com a literatura, ambientes xéricos (secos) possuem melhor difusão gasosa (Lacey 2000). As propriedades do ambiente onde se encontram as populações estudadas possuem características de ambientes xéricos, como solo arenoso e relativamente seco (Rebelato 2006) o que pode explicar os valores encontrados.

Os outros parâmetros hematológicos não apresentaram nenhuma diferença significativa entre os sexos.

Os resultados de hemograma entre as três populações distintas se encontram no Quadro 3. Os animais capturados na área $A$ apresentavam-se bastante parasitados por pulgas em comparação as outras duas áreas do estudo. Infestações parasitárias podem gerar uma eosinofilia em um organismo animal, em resposta a ectoparasitas e endoparasitas (Feldman et al. 2000). Em comparação aos animais das áreas $\mathrm{B}$ e $\mathrm{C}$, os quais não apresentavam afecções maciças a ectoparasitas, os roedores parasitados da área $A$ não obtiveram elevações na contagem diferencial de eosinófilos. Neste estudo, não foram realizados outros exames para a detecção de endoparasitas. Embora muitos estudos tenham sido feitos em roedores domésticos, não existem muitos estudos em roedores de vida livre com o objetivo de tentar entender os mecanismos de defesa destes contra ataques parasitários. Os ectoparasitas utilizam uma estratégia de diminuir a resposta imune de defesa do hospedeiro a um nível que facilite a sua alimentação, mas que não promova a mortalidade do mesmo, sendo que sinais clínicos de animais doentes geralmente não têm sido observados em resposta a infestação parasitária em pequenos mamíferos silvestres de vida livre. A manifestação destes sinais pode ser considerada como uma resposta não adaptativa a infecções parasitárias crônicas (Morandi et al. 2006). Severas infestações por pulgas podem levar os animais a quadros de anemia e debilitação (Patton 2000). Nenhum dos animais parasitados demonstrava sinais de debilidade ao exame clínico e tampouco anemia ao se avaliar o exame sanguíneo.

Ao analisarem-se os leucócitos totais entre as populações A e B, nota-se uma contagem mais elevada nestas áreas em comparação à área $C$, porém não estatisticamente significativa. Junto a isto, observa-se uma linfocitose acentuada nestas mesmas áreas, $A$ e $B$, estatisticamente significativas em comparação a área $\mathrm{C}$. Em cães, existem relatos de linfocitoses ligadas a estimulações antigênicas crônicas por fungos, hemoparasitas, protozoários e bactérias (Feldman et al. 2000). A relação entre parasita e hospedeiro em animais selvagens ainda não é bem elucidada, o que leva a pensar que possa existir alguma relação entre populações muito parasitadas e a estimulação crônica do sistema imune desses animais, fazendo com que variações no leucograma possam diferir daquelas conhecidas para animais domésticos.

Linfocitoses são observadas em respostas a excitação e estresse devido à liberação de epinefrina em respostas a "fuga e luta" nos animais. Dessa forma o leucograma demonstra aumentos significativos de leucócitos totais causados pela elevação de neutrófilos e linfócitos, ou somente uma dessas linhagens de células (Thrall 2004). Nenhum dos procedimentos de captura, contenção e coleta diferiram entre as áreas, porém, não se descarta a possibilidade dos indivíduos da população A e B terem manifestado maior excitação durante estes procedimentos, fato este, de difícil mensuração. Os valores de leucócitos totais também não apresentam diferenças significativas entre as três áreas, no entanto, os valores mais elevados são encontrados nas áreas A e B. Dessa forma, uma leucocitose com linfocitose, faz pensar que possa existir uma relação maior de resposta celular ao estresse nessas áreas. Analisando as três áreas, percebeu-se que a área $C$ não apresenta nenhuma ação antrópica em comparação às outras duas áreas, o que leva a acreditar que o pisoteio do gado, juntamente com atividades de manejo de pastagens e do solo possam estar causando algum tipo de impacto estressante sobre as áreas $\mathrm{A}$ e $\mathrm{B}$.

Variações significativas de $\mathrm{Hb}$ e $\mathrm{CHCM}$ foram detectadas nas áreas $A$ e $B$ em relação à área $C$. Estudos feitos em humanos comprovam que a $\mathrm{Hb}$ é um eficiente indicador para avaliação da resposta do organismo à suplementação de ferro na dieta (Mei et al. 2005). Isto sugere que as áreas com pastagem cultivada podem conter uma maior quantidade de Fe na alimentação dos animais se comparados com a pastagem nativa, fazendo com que ocorram variações na quantidade de $\mathrm{Hb}$ nas populações dessas áreas. Sendo o CHCM o índice que indica a concentração de hemoglobina nos eritrócitos, este também apresenta aumentos nos animais das áreas $A$ e B em comparação à área $C$.

A média do hematócrito encontrado nos animais das áreas $A$ e $B$ foi mais elevada em relação à área $C$, porém somente a área $A$ demonstrou diferenças significativas em relação à área C. A compactação dos solos causada pelo pisoteio do gado ou o tráfego de máquinas agrícolas aumenta a densidade e reduz a porosidade do solo. A alteração destas características pode determinar mudanças na condutividade interna, na permeabilidade e na difusão da água e do ar através do sistema poroso (Carrasco 1989). Em vista disto, as áreas impactadas podem ter uma maior densidade do solo e menor porosidade deste devido à compactação dos solos, o que poderia causar um aumento da pressão de $\mathrm{CO}_{2}$ nos túneis e consequentemente um aumento no hematócrito e na hemoglobina dessas populações.

Variações significativas no VCM foram encontradas en- 
tre as áreas $\mathrm{A}$ e $\mathrm{C}$, e também nas plaquetas entre as áreas A e B. Não se encontrou justificativas para tal variação.

Na contagem diferencial de leucócitos não foram constatados Corpúsculo de Kurloff. Acredita-se que esta ausência pode estar relacionada com a possível ausência de fêmeas prenhes entre os animais analisados ou com o fato desses animais realmente não apresentem esses corpúsculos em nenhuma fase da vida.

\section{CONCLUSÕES}

Os valores de hematócrito e hemoglobina encontrados para a espécie de roedor subterrâneo Ctenomys lami possuem diferenças entre os sexos e também diferenças em comparação a outros roedores com o mesmo hábito de vida.

Diferenças também foram encontradas em outros parâmetros entre as populações das três áreas estudadas.

Parece haver, de maneira geral, um conjunto de alterações metabólicas presente nas áreas impactadas pelo ser humano, onde a presença de gado e manejo dos solos alteram as propriedades físicas do solo, ambiente intimamente ligado ao modo de vida da espécie estudada.

Devido a não se encontrarem dados na literatura sobre parâmetros hematológicos de animais do gênero Ctenomys, acreditamos que este trabalho pode embasar estudos futuros sobre a fisiologia sanguínea nesses roedores subterrâneos.

\section{REFERÊNCIAS}

Arieli R., Ar A. \& Shkolnik A. 1977. Metabolic responses of a fossorial rodent (Spalax ehrenbergi) to simulated burrow conditions. Physiological Zoology 50:61-75.

Buffenstein R. 2000. Ecophysiological responses of subterranean rodents to underground habitats, p.62-110. In: Lacey E.A., Patton J.P. \& Cameron G.N. (Eds), Life Underground: The biology of subterranean rodents. University of Chicago Press, Chicago.

Comparatore V.M., Cid M.S. \& Bush C. 1995. Dietary preferences of two sympatric subterranean rodent population in Argentina. Revta Chilena Historia Natural 68:197-206.

Dean M.F. \& Muir H. 1970. The characterization of a proteinpolysaccharide isolated from Kurloff cells of the guinea pig. Biochem. J. 118:783-790.

Debout C., Quillet M. \& Izard J. 1984. Natural killer activity of Kurloff cells: A direct demonstration on purified Kurloff cell suspensions. Cellular Immunol. 87:674-677.

Debout C., Quillet M. \& Izard J. 1999. New data on the cytolytic effects of natural killer cells (Kurloff cells) on a leukemic cell line (guinea pig L2C). Leukemia Res. 23(2):137-147.

Eremin O., Wilson A.B., Coombs R.R., Plumb D. \& Ashby J. 1980.
Antibody-dependent cellular cytotoxity in the guinea pig: The role of the Kurloff cells. Cellular Immunol. 55:312-327.

Freitas T.R.O. 1990. Estudos citogenéticos e craniométricos em três espécies do gênero Ctenomys. Tese de Doutorado, Curso de PósGraduação em Genética e Biologia Molecular, UFRGS, Porto Alegre, RS. 235p.

Freitas T.R.O. 2001. "Tuco-tucos" (Rodentia - Octodontidae) in southern Brazil: Ctenomys lami spec. nov. separated from C. minutus Nehring 1887. Studies on Neotropical Fauna and Environment 36:1-8.

Hawkey C.M. \& Dennet T.B. 1989. Comparative Veterinary Haematology. W.S. Cowell, Ipswich. 192p.

Jain N.C. 1986. Schalm's Veterinary Hematology. $4^{\text {th }}$ ed. Lea and Febiger, Philadelphia. 1221p.

Jara L.F., Sanchez J.M., Alvarado H. \& Nassar-Montoya F. 2005. Kurloff cells in peripheral blood and organs of wild capybaras. J. Wildl. Dis. 41(2):431-434.

Johansen K., Lykkeboe G., Weber R.E. \& Maloiy G.M. 1976. Blood respiratory properties in the naked mole-rat, Heterocephalus glaber, a mammal of low body temperature. Respiratory Physiol. 28:303-314.

Lacey E.A., Patton J.P. \& Cameron G.N. 2000. Life Underground: The biology of subterranean rodents. University of Chicago Press, Chicago. 449p.

Lechner A.J. 1976. Respiratory adaptation in burrowing pocket gophers from sea level and high altitude. J. Appl. Physiol. 41:168-173.

Maclean G.S. 1981. Factors influencing the composition of respiratory gases in mammal burrows. Comp. Biochem. Physiol. 69:373-383.

Mei Z., Cogswell M.E., Paryanta I., Lynch S. \& Bear J.L. 2005. Hemoglobin and Ferritin are currently the most efficient indicators of population response to iron interventions: An analysis of nine randomized controlled trials. J. Nutrition 135:1974-1980.

Patton S. 2000. Rabbit and ferret parasite testing, p.258-365. In: Fudge A.M. (Ed.), Laboratory Medicine Avian and Exotic Pets. Saunders, Pennsylvania.

Rebelato G.S. 2006. Análise ecomorfológica de quarto espécies de Ctenomys do sul do Brasil (Ctenomyidae - Rodentia). Dissertação de Mestrado, Programa de Pós-Graduação em Ecologia, UFRGS, Porto Alegre. 145p.

Reig O.A., Busch C., Ortells M.O. \& Contreras J.R. 1990. An overview of evolution, systematics, population and speciation in Ctenomys, p.71-96 In: Nevo E. \& Reig O.A. (Eds), Evolution of Subterranean Mammals at the Organism and Molecular Levels. Liss, New York.

Widmer H.R., Hopperler H., Nevo E., Taylor C.R. \& Weibel E.R. 1997. Working underground: Respiratory adaptations in the blind mole rat. Proc. Natl Acad. Sci. 94:2062-2067.

Williams L.R. \& Cameron G.N. 1986. Food habits and dietary preferences of Attwater's pocket gopher, Geomys attwateri. J. Mammalogy 67:216-24.

Woods C.A. \& Kilpatrick C.W. 2005. Hystricognathi, p.1538-1600. In: Wilson D.E. \& Reeder D.M. (Eds), Mammal Species of the World: A taxonomic and geographic reference. Johns Hopkins University Press, Baltimore. 